\title{
Metal-mediated synthesis of furans and pyrroles
}

\author{
Nitin T. Patil and Yoshinori Yamamoto* \\ Department of Chemistry, Graduate School of Science, Tohoku University, \\ Sendai 980-8578, Japan \\ E-mail: yoshi@mail.tains.tohoku.ac.jp
}

Dedicated to Professor Alan Krief on the Occasion of his $65^{\text {th }}$ Birthday

\begin{abstract}
The transition metal catalyzed synthesis of furans and pyrroles is becoming an important and highly rewarding protocol in organic synthesis. This review focuses on the use of transition metal as a catalyst for the synthesis of furans and pyrroles along with their interesting mechanistic aspects. The synthetic efforts in this area will clearly culminate in tackling the major issues pertaining to atom economy and environmentally acceptable technologies for future.
\end{abstract}

Keywords: Metal catalysis, furans, pyrroles, cascade cyclization

\section{Introduction}

Highly substituted furans ${ }^{1}$ and pyrroles $^{2}$ are a structural component of a vast number of biologically active natural and unnatural compounds. Synthesis of them has been the objective of research for over a century, and a variety of well-established classical methods are now available in the literature. ${ }^{3}$ Development of newer approaches for heterocycle syntheses employing efficient and atom economical routes is popular research area nowadays. Among a variety of new synthetic transformations, transition metal catalyzed reactions are the most attractive methodologies, since those reactions can directly construct multiply substituted molecules from readily accessible starting materials under mild conditions. ${ }^{4}$ The formation of furans and pyrroles by using various transition metals has been investigated in the literature. Since the synthesis of these heterocycles is thoroughly reviewed up to 1999 and 2001, respectively, this review will discuss recent advances for the synthesis of furans and pyrroles focusing on the use of transition metals. ${ }^{5}$ It should be noted that the reactions in which a heterocyclic ring is essentially generated are only described. Other reactions in which a heterocyclic ring already exists in the molecule and a transition metal catalyzes the further structural manipulations are not described here. 
It is reported that cyclization of allenyl ketone $\mathbf{1}$ provided furan $\mathbf{2}$ in the presence of catalytic amounts of $\mathrm{AuCl}_{3}$. The reaction was extended also to one pot selective cross cycloisomerization/dimerization of $\mathbf{3}$ with $\alpha, \beta$-unsaturated ketones $\mathbf{4}$ to give $\mathrm{C}-2$ substituted furans 5 (Scheme 1). ${ }^{6}$ The mechanism of the reaction is shown in Scheme 2. The authors believed the intermediacy of 7 and proposed two possibilities for the formation of it. Either the $\mathrm{AuCl}_{3}$ activates the enones 4 to form 8, which then create the new $\mathrm{C}-\mathrm{C}$ bonds by an electrophilic aromatic substitution at the 5-position of the furan to provide 7 (path A), or a cyclization of 3 under gold catalysis forms a furyl-gold species $\mathbf{6}$, which subsequently undergoes a 1,4-addition to the Michael acceptor (path B). The intermediate 7 then undergoes proto-dematallation to form 5 along with regeneration of the gold catalyst. Recently, gold(III) porphyrin complexes have been utilized for the cyclization of allenones. ${ }^{7}$
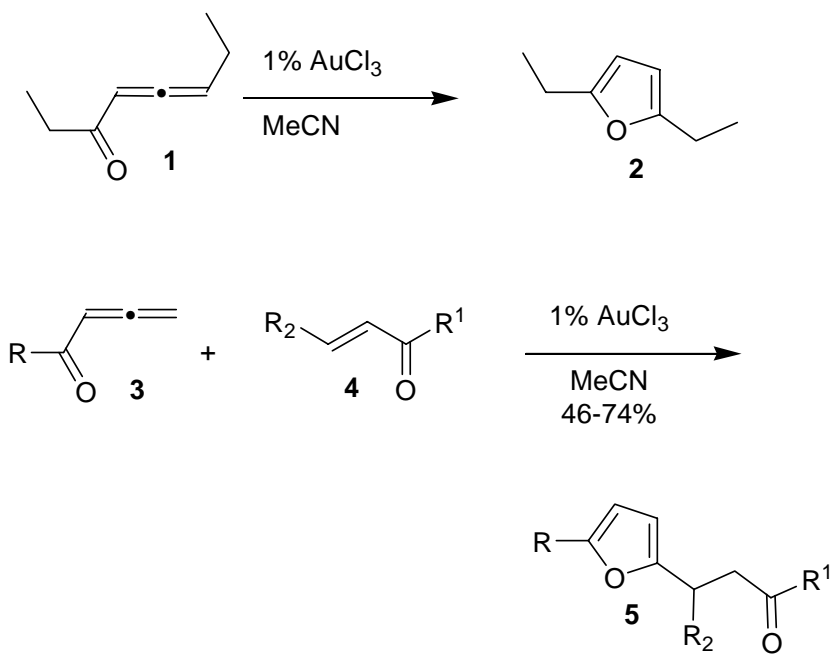

\section{Scheme 1}

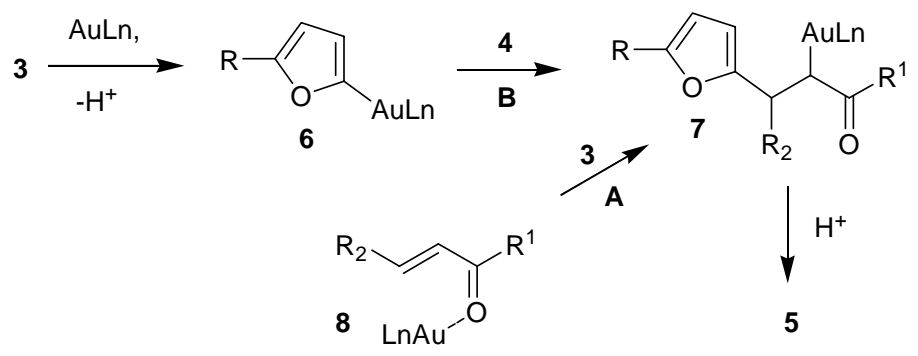

Scheme 2

Gevorgyan et al. have shown that 1,2-iodine, -bromine, and -chlorine migration in haloallenyl ketones 9 takes place in the presence of $\mathrm{AuCl}_{3} .{ }^{8}$ For this reaction iodo and bromo allenyl ketones gave best results, compared to their chloro analogue. This chemistry is interesting not only as a novel cascade transformation but also serves as a mild, selective, and efficient approach to different types of 3-halofurans 10. It was reported that the reaction proceeded through halirenium intermediate 12, formed by the intramolecular Michael addition of $\mathrm{X}$ to the 
enone moiety as shown in 11, which via subsequent addition-elimination furnishes 3-halofurans 10 (Scheme 3). It is interesting to note that just by switching solvent from toluene to THF caused a dramatic change in selectivity affording 2-bromofurans as the major product.
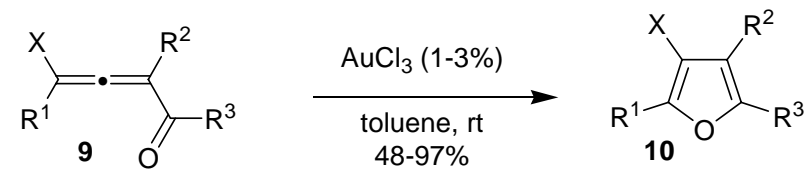

$$
\mathrm{X}=\mathrm{Br}, \mathrm{I}, \mathrm{Cl}
$$

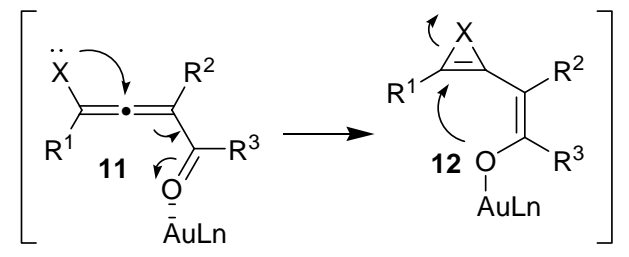

\section{Scheme 3}

Gevorgyan and coworkers have shown that alkynes can also be used, instead of allenes, for such transformations. They developed an efficient method for the synthesis of 2-monosubstituted and 2,5-disubstituted furans 14 via the CuI catalyzed cycloisomerisation of alkynyl ketones 13 (Scheme 4). ${ }^{9}$ It was demonstrated that furans containing both acid and base labile groups could be easily synthesized using this methodology. Pioneering work from the same group revealed that 3-thio substituted furans $\mathbf{1 6 a}$ and pyrroles $\mathbf{1 6 b}$ could be easily obtained from propargyl ketones 15a and propargyl imines 15b, respectively, by heating in $N, N$-dimethylacetamide in the presence of $\mathrm{CuI}$ (Scheme 5). ${ }^{10}$ The key in the mechanism was the 1,2 migration of the Y group from $\mathrm{sp}^{2}$ carbon atom in allenyl species as shown in intermediate $\mathbf{1 7}$ and $\mathbf{1 8 .}$

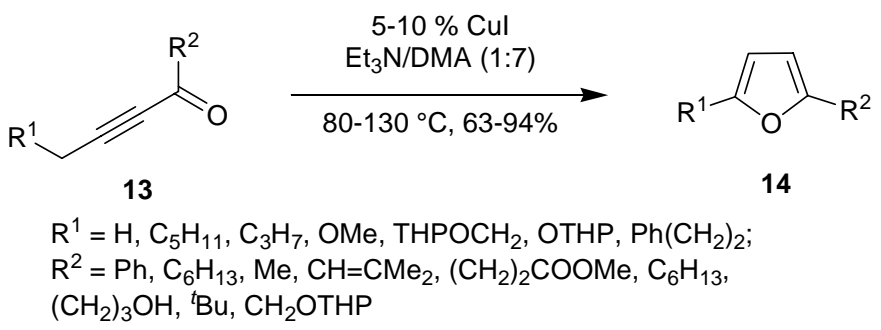

\section{Scheme 4}




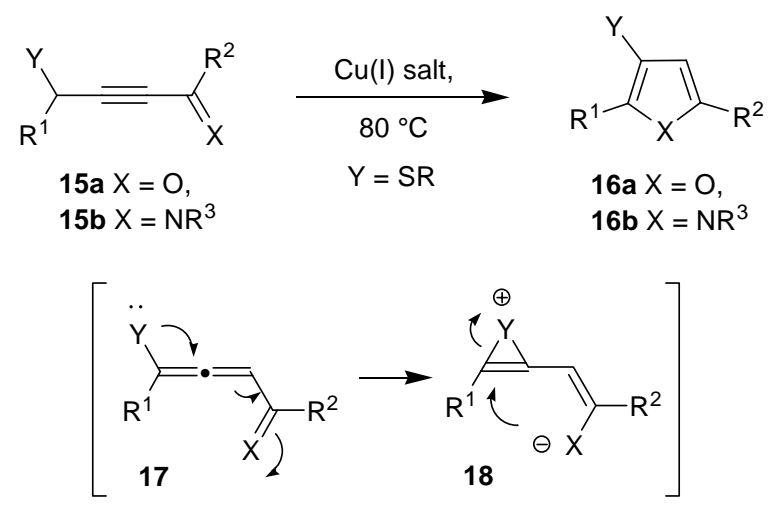

\section{Scheme 5}

The same group reported a new method for the synthesis of furans $\mathbf{2 0}$ from alkynyl ketones 19 via 1,2 migration of acetate groups (Scheme 6). ${ }^{11}$ The reactions were conducted in the presence of $5 \mathrm{~mol}^{\circ} \mathrm{AgBF}_{4}$ and at room temperature. Not only acetate group but also $\mathrm{OP}(\mathrm{O})(\mathrm{OEt})_{2}$ and -OTs group were migrated, however, somewhat high temperature $\left(60^{\circ} \mathrm{C}\right)$ was needed in order to complete the reaction. The reaction involves the intermediacy of allene 21. This is the first example of 1,2-migration of acyloxy, phosphatyloxy and sulfonyloxy groups from $\mathrm{sp}^{2}$ carbon.

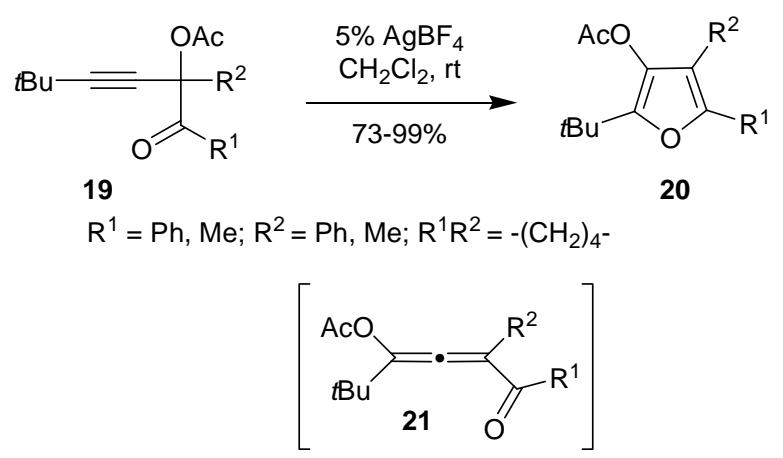

\section{Scheme 6}

The reaction of propargyl ketone such as 22 in the presence of $0.1 \mathrm{~mol} \% \mathrm{AuCl}_{3}$ at $20{ }^{\circ} \mathrm{C}$ gave the furan 23 in essentially quantitative yield (Scheme 7).Error! Bookmark not defined. On the other hand, with palladium as a catalysts, heating at $100{ }^{\circ} \mathrm{C}$ was needed in order to proceed the reaction. A novel cascade cyclization of the propargyl ketone $\mathbf{2 4}$ for the formation of $\mathbf{2 6}$ in the presence of $\mathrm{AuCl}_{3}$ was also reported in the same paper. The authors proposed the intermediacy of 25 for this cascade cyclization. 

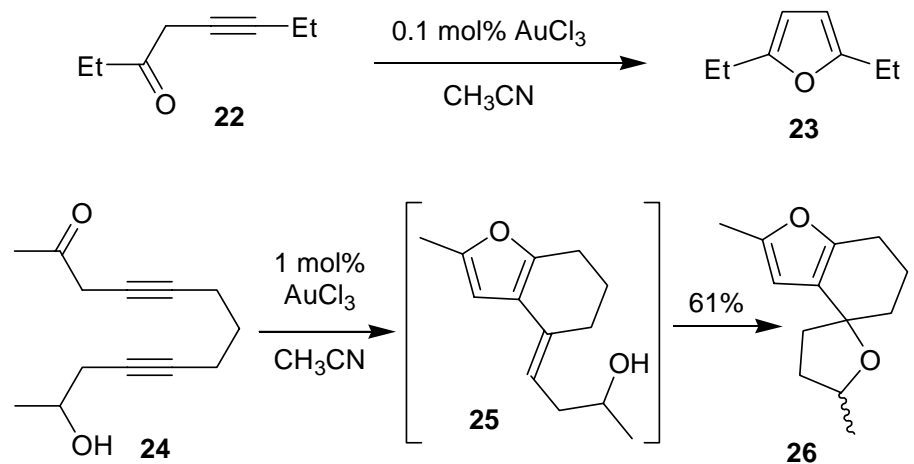

\section{Scheme 7}

The introduction of substituents at the C-4 position of the corresponding furans using a transition metal catalyzed cycloisomerization approach is generally considered as difficult task. Recently, Ma and co-workers reported palladium catalyzed cross coupling cyclization sequence to produce tetrasubstituted furan $\mathbf{2 8}$ from allenyl ketones 27 and $p$-iodoanisole (Scheme 9). ${ }^{12}$ The species 29 was proposed as an intermediate.
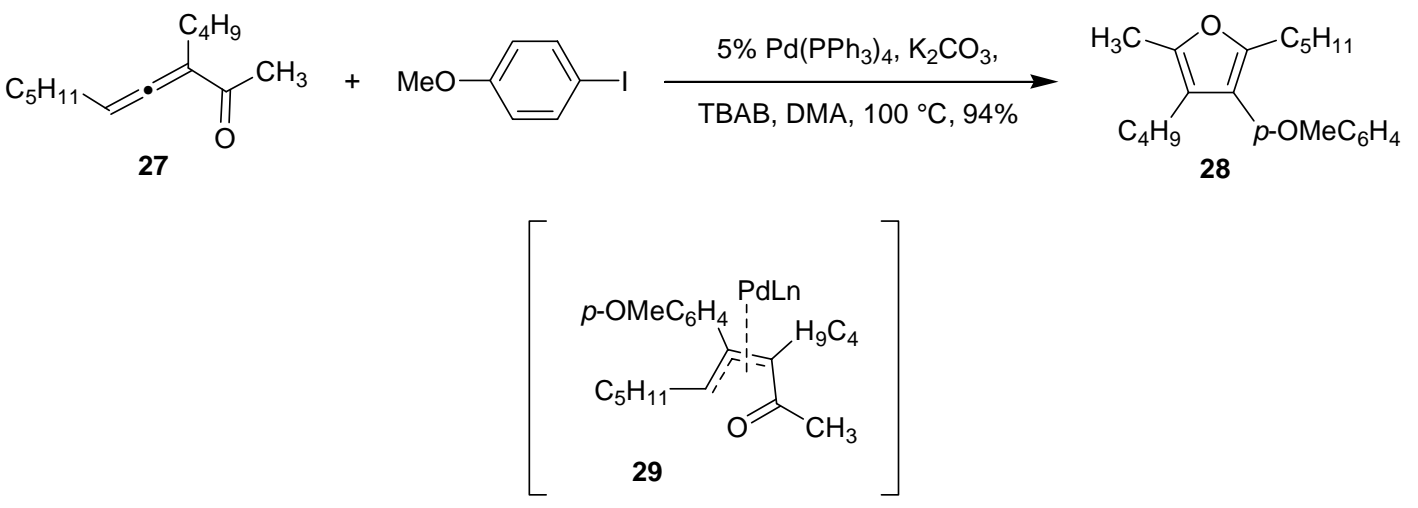

\section{Scheme 8}

An isomerization of alkynyl epoxides $\mathbf{3 0}$ into furans $\mathbf{3 1}$ in the presence of gold(III) chloride took place at room temperature (Scheme 9). ${ }^{13}$ The coordination of the triple bond of 30 to $\mathrm{AuCl}_{3}$ enhances the electrophilicity of alkyne (cf 32), and the subsequent nucleophilic attack of the epoxide oxygen at the distal position of alkyne forms the species 33, which on isomerizationdeprotonation-protodemetalation (cf 34 and 35) gives furans 31 (Scheme 10).

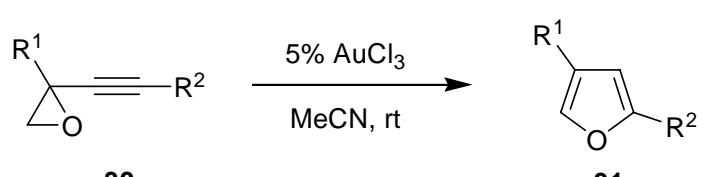

\section{Scheme 9}




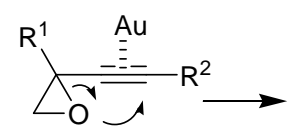

32

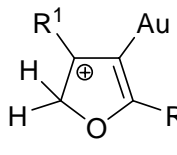

33
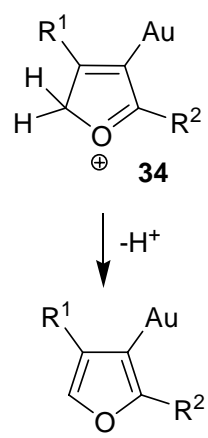

35

\section{Scheme 10}

Kirsch and coworkers recently described the synthesis of highly substituded furans $\mathbf{3 7}$ from 36 mediated by gold(I) species. ${ }^{14}$ The reaction is accomplished at room temperature just by using $2 \mathrm{~mol} \%$ catalyst loading. A mechanism for the cascade cyclization involves the formation of $\beta$ allenic ketone 38 which then undergoes gold(I) catalyzed 5-exo-dig cyclization affording furans 37 (Scheme 11).
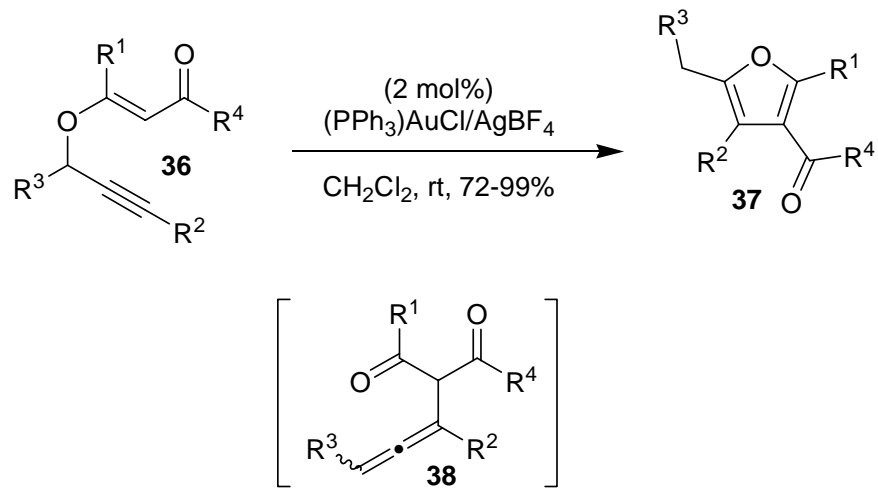

\section{Scheme 11}

Recently, Larock reported an entirely new approach for the novel cyclization of 2-(1alkynyl)-2-alken-1-ones 39 with nucleophiles in the presence of catalytic amounts of $\mathrm{AuCl}_{3}$ which led to the formation of highly substituded furans 40 (Scheme 12). ${ }^{15}$ Examples of nucleophiles include alcohols, activated methylenes and electron rich arenes such as $N, N$ dimethylaniline and $N$-methyl indole. The mechanism of the reaction is depicted in Scheme 13. The coordination of the triple bond of 39 to $\mathrm{AuCl}_{3}$ enhances the electrophilicity of the triple bond (cf 41), and subsequent nucleophilic attack of the carbonyl oxygen on the electron-deficient triple bond generates carbocation 42. Intermolecular nucleophilic attack of nucleophiles on the carbocation gives furyl gold species 43 , which after protonation of the carbon-gold bond affords furans 40 and regenerates the catalyst $\mathrm{AuCl}_{3}$. The authors ruled out the possibility of an 
alternative mechanism wherein $\mathrm{AuCl}_{3}$ first acts as a Lewis acid, forming a complex with the carbonyl oxygen thereby facilitating Michael addition. We later showed that inexpensive and air stable $\mathrm{Cu}(\mathrm{I})$ in DMF could also be used as a catalyst for this reaction. ${ }^{16}$

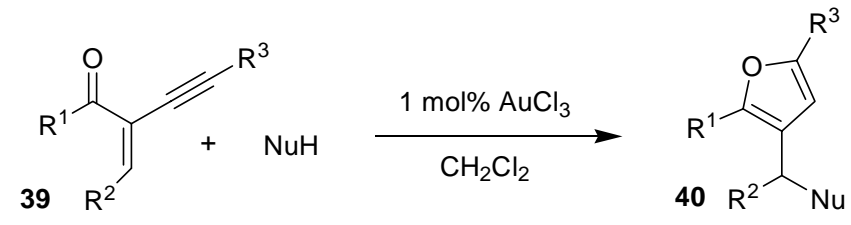

\section{Scheme 12}

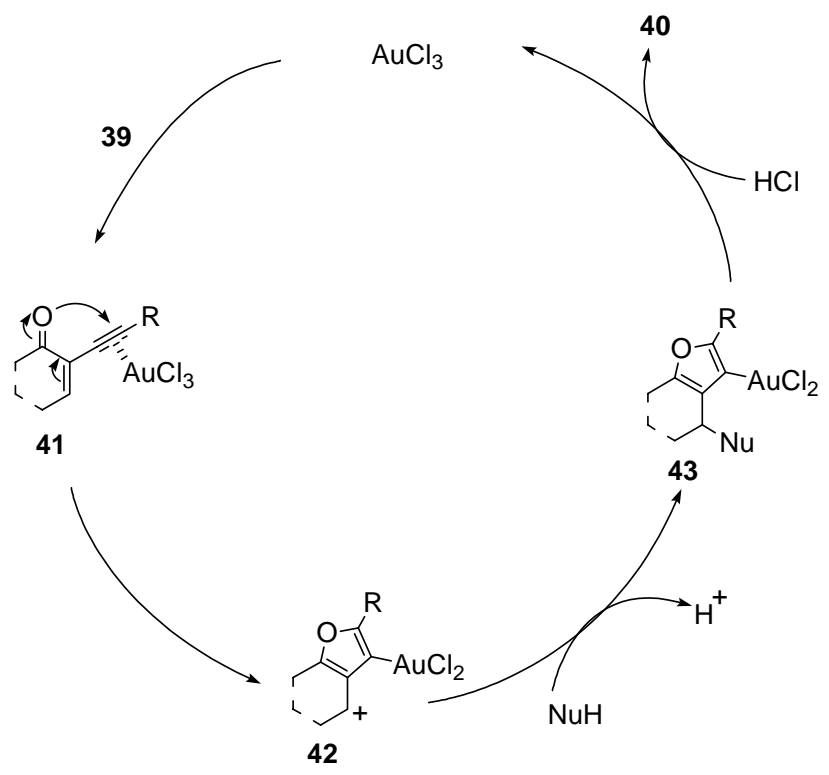

\section{Scheme 13}

Recently, Schmalz and Zhang reported the gold catalyzed atom economical cascade cyclization of the substrates of type 44 (Scheme 14). ${ }^{17}$ The process provided efficient access to highly substituted furans $\mathbf{4 5}$ under mild conditions. A variety of nucleophiles, such as alcohols (including tert-butanol), phenols, or acetic acid can be used for the reaction. The preparation of the substrate is also easy and they can be prepared by the cyclopropanation of corresponding enones. Two different intermediates $\mathbf{4 6}$ and $\mathbf{4 7}$ were proposed for this reaction. 

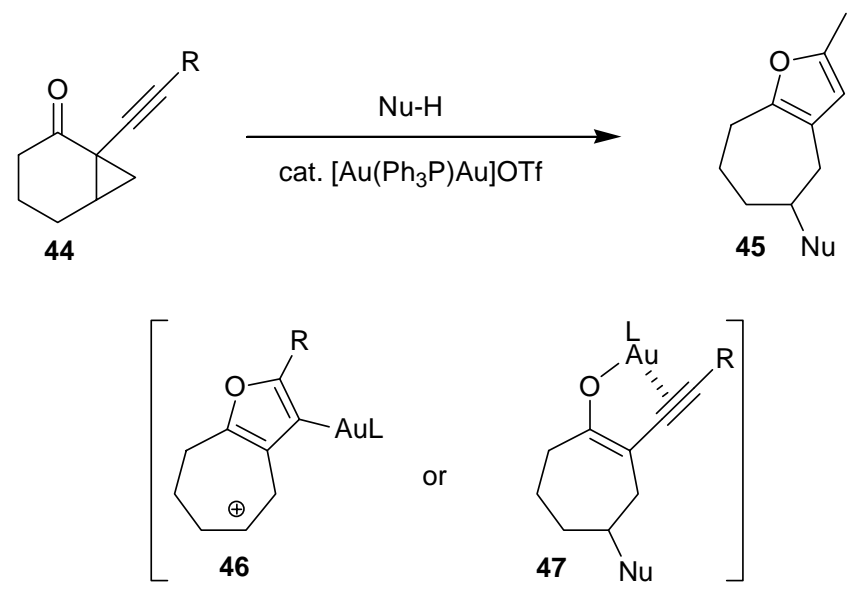

\section{Scheme 14}

Ma and Zhang developed copper (I) catalyzed regioselective cycloisomerization of cyclopropenyl ketones 48 into 2,3,4-trisubstituted furans 49 (Scheme 15). ${ }^{18}$ The regeoselective iodocupration of the $\mathrm{C}=\mathrm{C}$ bond of $\mathbf{4 8}$ produces $\mathbf{5 0}$ which on subsequent $\beta$-decarbocupration gives delocalized intermediate 51. The intramolecular endo-mode insertion of the $\mathrm{C}=\mathrm{C}$ bond into the oxygen-copper bond of intermediate 51 and subsequent $\beta$-halide elimination of intermediate 52 affords 49 with the regeneration of $\mathrm{CuI}$. They also reported the isomerization of 53 into furan 54 in refluxing acetone in the presence of $\mathrm{PdCl}_{2}\left(\mathrm{CH}_{3} \mathrm{CN}\right)_{2}$ and 2 equiv of sodium iodide (Scheme 16). ${ }^{19}$

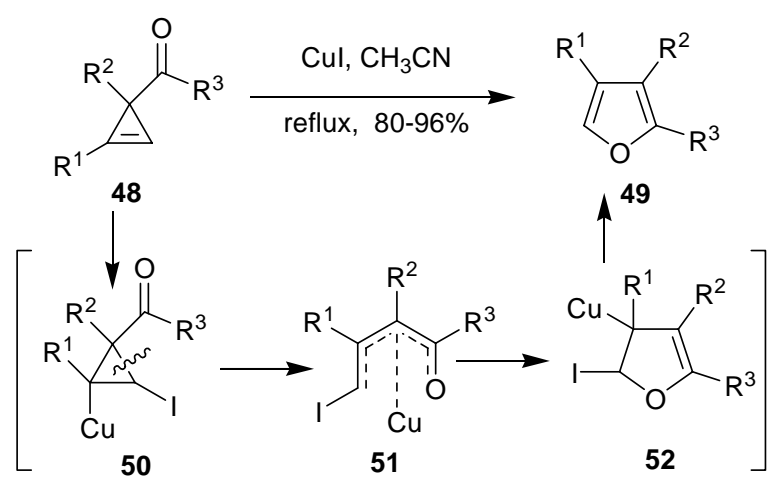

\section{Scheme 15}




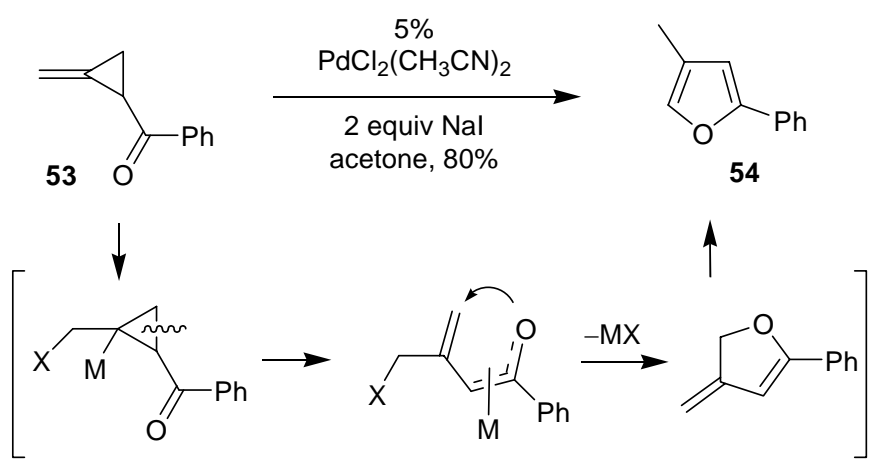

\section{Scheme 16}

The gold-catalyzed cyclization of (Z)-enynols 55 afforded ( $Z$ )-5-ylidene-2,5-dihydrofurans 56 and fully substituted furans 57 depending on the nature of $\mathrm{R}^{1}$ group (Scheme 17). ${ }^{20}$ For instance, when $\mathrm{R}=$ alkyl or aryl, 56 was formed. On the other hand when $\mathrm{R}=\mathrm{H}$, 57 was obtained. Two reaction conditions were employed; i) $\mathrm{AuCl}_{3}$ in $\mathrm{CH}_{2} \mathrm{Cl}_{2}$ ii) $\left(\mathrm{PPh}_{3}\right) \mathrm{AuCl} / \mathrm{AgOTf}$. Both of them generally gave products in high yields.
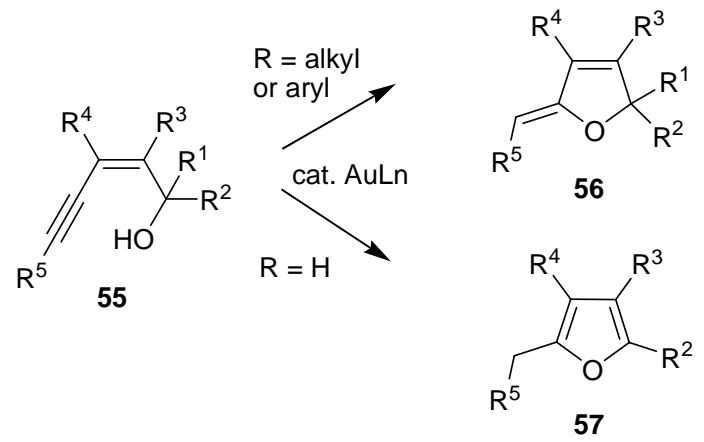

\section{Scheme 17}

A novel one pot procedure for the synthesis of functionalized furan derivatives 59, from 58, propargyl alcohol and iodobenzene, has been reported by Balme et al. (Scheme 18). ${ }^{21}$ It involves a conjugate addition between $\mathbf{5 8}$ and propargyl alcohol, a palladium-catalyzed couplingcyclization (cf 60), an alkoxide-induced decarboxylative elimination (cf 61), and finally, a double bond isomerization ( $\mathrm{cf} \mathbf{6 2})$. 


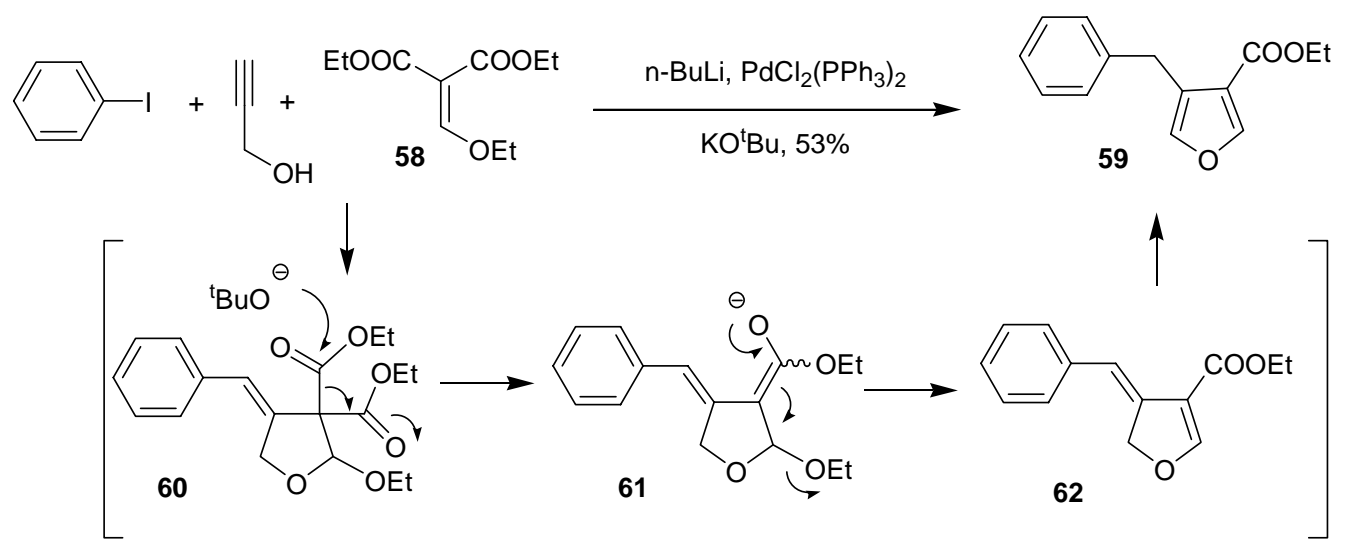

\section{Scheme 18}

A novel sequence of Sonogashira coupling and electrophilic addition to an ynone, with concomitant deprotection and cyclocondensation, opens a new one-pot synthesis of 3-halofurans; the method can be readily elaborated to a new sequential Sonogashira-additioncyclocondensation-Suzuki reaction to furnish 2,3,5-trisubstituted furans in a one-pot fashion. For example, reaction of $\mathbf{6 3}$ with $\mathbf{6 4}$ in the presence of Pd-Cu bimetallic system formed $\mathbf{6 6}$ which on treatment with PTSA gives 65 via intermediates 67 and 68 (Scheme 19). ${ }^{22}$

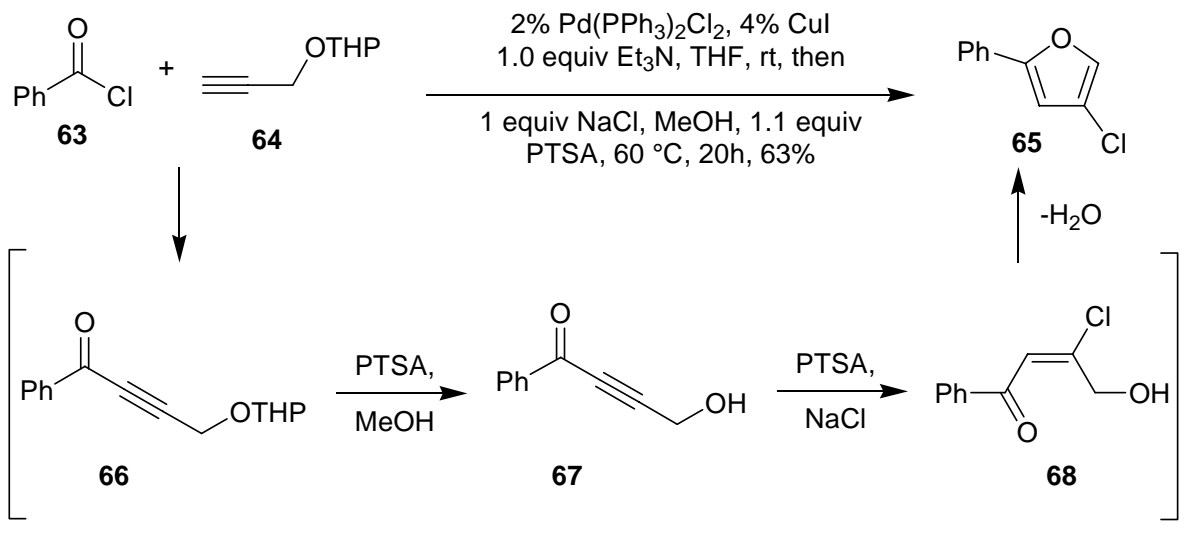

\section{Scheme 19}

Widenhoefer and Han developed an efficient, one-pot procedure for the conversion of $\alpha$ alkenyl $\beta$-diketones to 2,3,5-trisubstituted furans (Scheme 20). ${ }^{23}$ Treatment of 4-allyl-2,6dimethyl-3,5-heptanedione 69 with a catalytic amount of $\mathrm{PdCl}_{2}\left(\mathrm{CH}_{3} \mathrm{CN}\right)_{2}(5 \mathrm{~mol} \%)$ and a stoichiometric amount of $\mathrm{CuCl}_{2}$ (2.2 equiv) in dioxane at $60{ }^{\circ} \mathrm{C}$ for $12 \mathrm{~h}$ formed 3-isobutyryl-2isopropyl-5-methylfuran $\mathbf{7 0}$ in $\mathbf{7 7 \%}$ isolated yield. A number of $\alpha$-alkenyl $\beta$-diketones underwent oxidative alkoxylation under these conditions to form 2,3,5-trisubsituted furans in moderate to good yield. Mechanistically, nucleophilic attack of enolic oxygen atom on the palladium- 
complexed olefin (cf 71) would form the palladium dihydrofurylmethyl intermediate 72 which undergo $\beta$-hydride elimination and proton migration to afford furan $\mathbf{7 0}$.
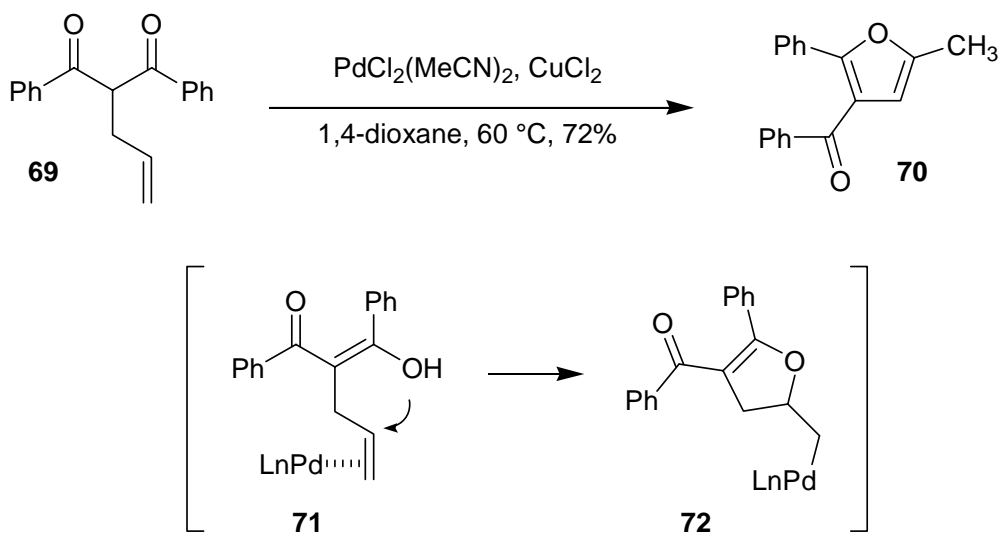

\section{Scheme 20}

Gevorgyan et al. reported a new route for the synthesis of pyrroles $\mathbf{7 4}$ via copper(I) catalyzed cyclization of alkynyl imines 73 (Scheme 21). ${ }^{24}$ Mechanistic studies revealed that this reaction proceeded via the propargyl-allenyl isomerization of $\mathbf{7 3}$ to the allenyl imines $\mathbf{7 5}$ and through the nucleophilic attack of the nitrogen atom of imine on the electron deficient carbon as shown in intermediate $\mathbf{7 6}$ which forms the copper containing pyrrole ring skeleton $\mathbf{7 7}$. Isomerization in $\mathbf{7 7}$, protonation and regenaration of the catalyst afford pyrroles 74. They also applied this methodology for the synthesis of indolizidines. The copper assisted reaction of the 2alkynylpyridines $\mathbf{7 8}$ provided the indolizidine derivatives $\mathbf{7 9}$ in good yields (Scheme 22). ${ }^{25}$ The copper assisted double cyclization of bis-alkynylpyrimidine $\mathbf{8 0}$ afforded the 5-6-5 tricyclic heteroaromatic skeleton $\mathbf{8 1}$ (Scheme 23). This transformation was used as a key step in the highly diastereoselective total synthesis of $( \pm)$-tetraponerine T6.

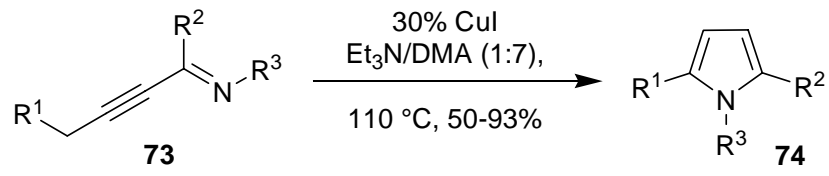

$\mathrm{R}^{1}={ }^{n} \mathrm{Bu}, \mathrm{CH}_{3}\left(\mathrm{CH}_{2}\right)_{3} \mathrm{CH}=\mathrm{CH}_{2}, \mathrm{CN}\left(\mathrm{CH}_{2}\right)_{2} \mathrm{CH}_{2}$, OTBSCH $\mathrm{CH}_{3}$, OTBS, $\mathrm{H},{ }^{n} \mathrm{Pr} ; \mathrm{R}^{2}=\mathrm{H},{ }^{n} \mathrm{Pr}, \mathrm{Ph}, \mathrm{Me} ; \mathrm{R}^{3}={ }^{n} \mathrm{Bu},{ }^{t} \mathrm{Bu}, \mathrm{Tr}$, 3-(ethylbutyryl), $\mathrm{Ph}$

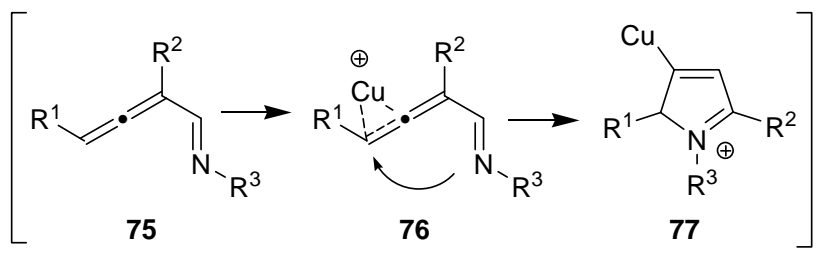

\section{Scheme 21}




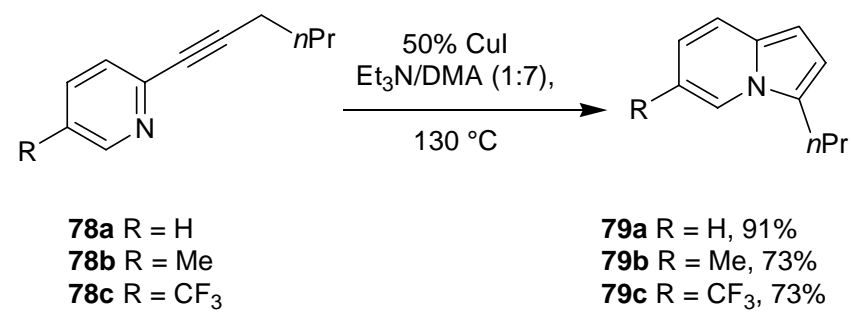

\section{Scheme 22}

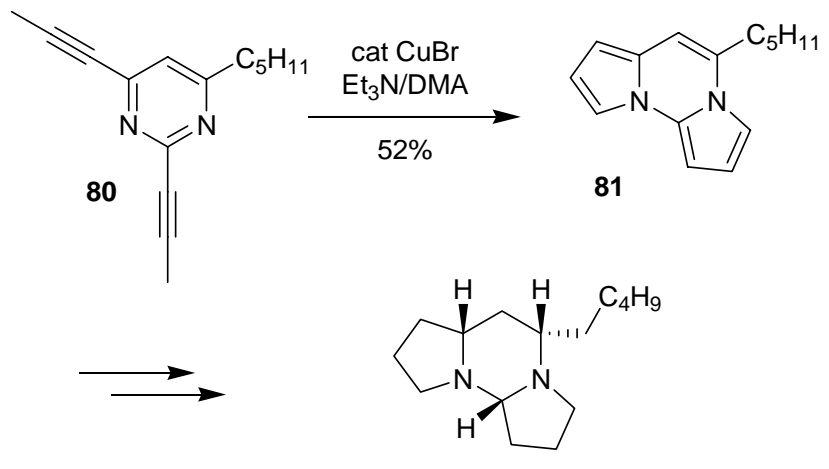

(+-)-tetraponerine T6

\section{Scheme 23}

A new gold catalyzed cascade cycloisomerization of propargylic derivatives 82 into pyrrole containing heterocycles 83 is known (Scheme 24). ${ }^{26}$ This cascade transformation involves 1,2migration of silyl, stannyl and germyl group and allows an efficient synthesis of various C-2 substituted fused pyrrole containing heterocycles. Mechanistcally, first isomerization of alkyne 82 results in the formation of vinylidene species $\mathbf{8 4}$ followed by nucleophilic attack of the nitrogen lone pair at the vinylidene carbon resulting in formation of zwitterions 85 which undergo a series of 1,2-hydride shifts to furnish 83.

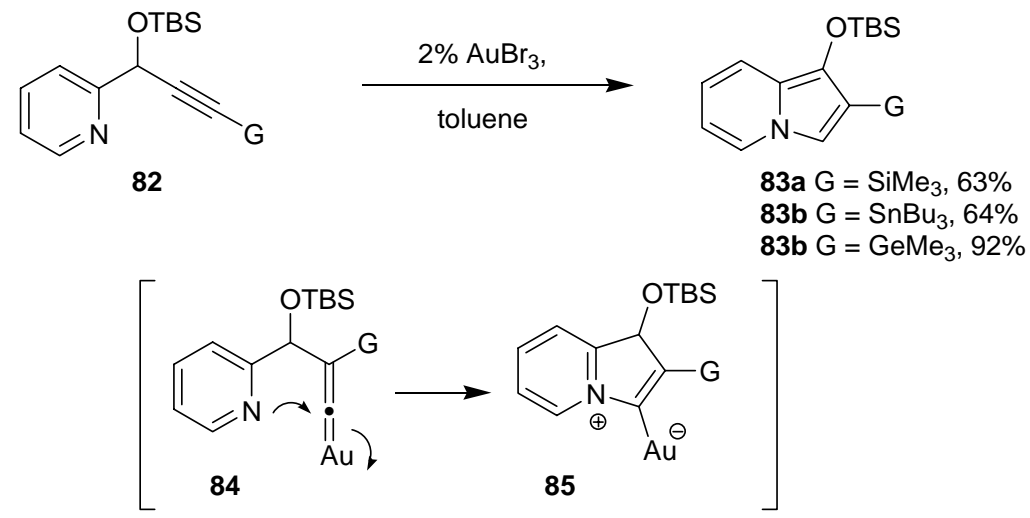

\section{Scheme 24}


The cyclization of (Z)-(2-en-4-ynyl)amines 86 into pyrroles 87 was reported by Gabriele and coworkers (Scheme 25). ${ }^{27} \mathrm{CuCl}_{2}$ was found to be an excellent catalyst for the cyclization of the substrates substituted at $\mathrm{C}-3$, while $\mathrm{PdX}_{2}$ in conjuction with $\mathrm{KX}(\mathrm{X}=\mathrm{Cl}, \mathrm{I})$ turned out to be a superior catalyst for the reaction of enynamines unsubstituted at C-3.

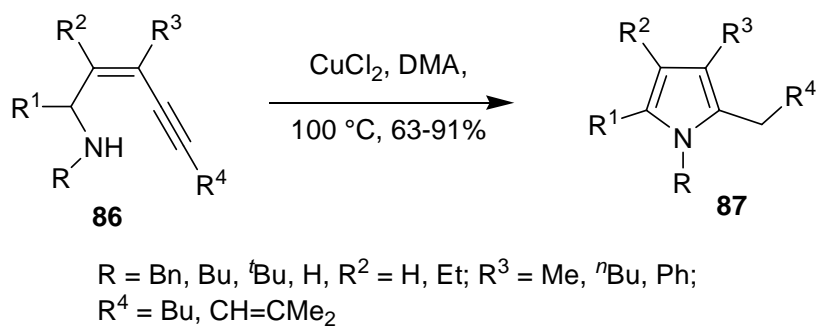

\section{Scheme 25}

The gold(III)-catalyzed sequential amination/annulation reaction of 2-propynyl-1,3dicarbonyl compounds $\mathbf{8 8}$ with primary amines produces 1,2,3,5-substituted pyrroles $\mathbf{8 9}$ in moderate to high yields (Scheme 26). ${ }^{28}$ The reaction of $\mathbf{8 8}$ with primary amines under the reaction conditions generates enaminone intermediate $\mathbf{9 0}$. The cyclization of $\mathbf{9 0}$ through 5-exodig pathway followed by protonolysis of the resulting $\mathrm{C}$-Au bond and subsequent isomerization reaction afford the pyrroles $\mathbf{8 9}$.
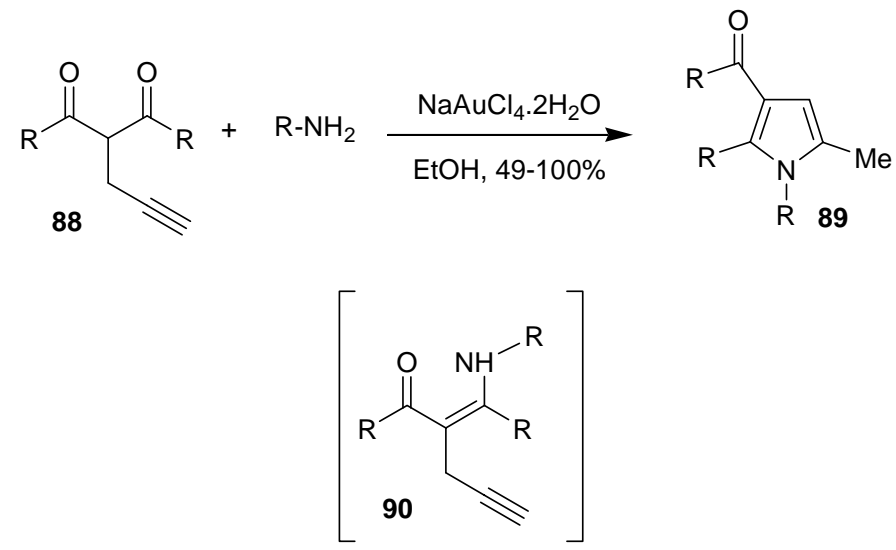

\section{Scheme 26}

Dake and coworkers reported a domino process for the synthesis of pyrroles 92 starting from ketoalkyne 91, and amines. Either silver trifluoromethanesulfonate or a mixture of gold(I) chloride, silver trifluoromethanesulfonate, and triphenylphosphine catalyze the formation of pyrroles from substituted $\beta$-alkynyl ketones and amines (Scheme 27). ${ }^{29}$ The reactions proceed by using $5 \mathrm{~mol} \%$ of catalyst with yields of isolated pyrroles ranging from $13 \%$ to $92 \%$. 

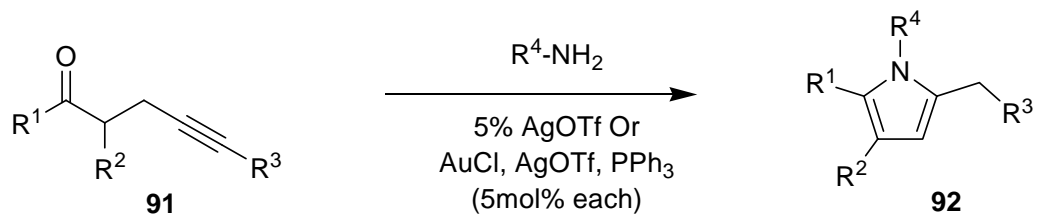

\section{Scheme 27}

A domino process involving copper catalyzed C-N coupling and intramolecular hydroamidation for the synthesis of pyrroles 94 from haloenynes 93 (via intermediate 95) was described by Buchwald and coworkers (Scheme 28). ${ }^{30}$ The reaction of a substrate bearing a terminal alkyne did not give the product, however, this transformation can be accomplished by the use of a-TMS group which masks the terminal acetylene and is deprotected in situ.

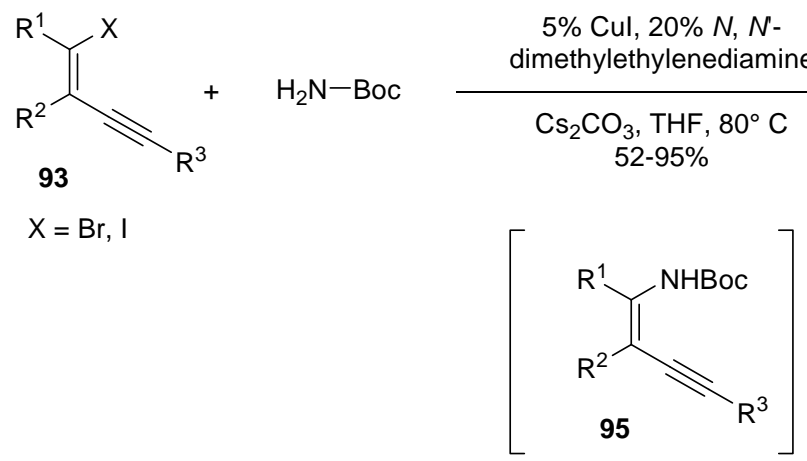

\section{Scheme 28}

Toste and coworkers developed gold(I) catalyzed intramolecular acetylenic Schmidt reactions of homopropargyl azides $\mathbf{9 6}$ for the synthesis of multiply substituded pyrroles $\mathbf{9 7}$ (Scheme 29). ${ }^{31}$ The reactions were performed under extremely mild conditions and preparation of the catalyst was also very easy. A new aspect of gold chemistry has been proposed; gold (I) serves as both to activate the alkyne to form $\mathbf{9 8}$ and also to donate electron density back into an electron deficient $\pi$-system as shown in 99. Recently, Hiroya et al. showed that $\mathrm{PtCl}_{4}$ in ethanol is also capable of catalyzing this reaction in the presence of suitable base. ${ }^{32}$ 


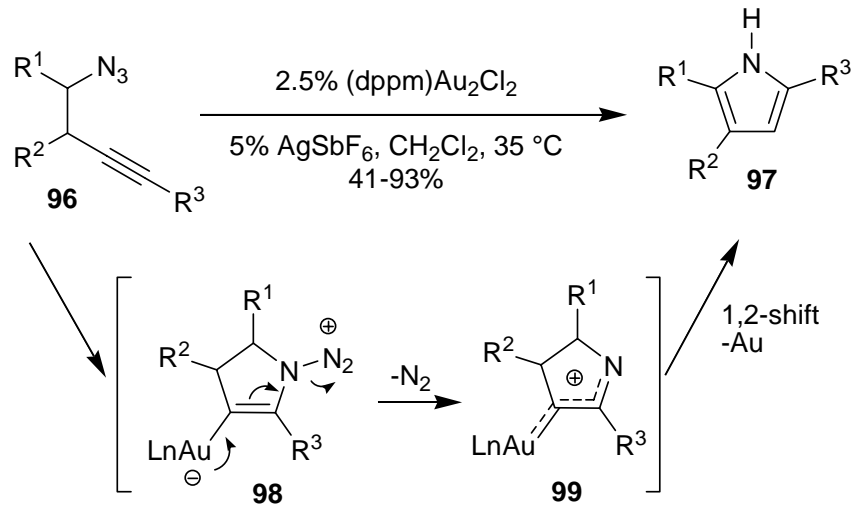

\section{Scheme 29}

The copper catalyzed reaction of isocyanides $\mathbf{1 0 0}$ with electron deficient alkynes $\mathbf{1 0 1}$ gave substituded pyrroles 102 (Scheme 30). ${ }^{33}$ Among the catalysts tested, the combination of $\mathrm{Cu}_{2} \mathrm{O}$ and 1,10-phenanthroline showed the highest catalytic activity. A proposed mechanism is illustrated in Scheme 31. The 1,4-addition of the nucleophilic intermediate 103a or 103b, generated from 100 with the extrusion of $\mathrm{H}_{2} \mathrm{O}$, to the alkynes 101 takes place first. The newly generated copper enolate would intramolecularly attack the isonitrile carbon to generate the cyclized intermediate 104. This process can be termed as a formal [ $3+2$ ] cycloaddition process. The $\mathrm{C}-\mathrm{Cu}$ bond in the intermediate $\mathbf{1 0 4}$ is protonated by isocyanides, and the intermediate 105 is produced with regeneration of the copper-intermediate 103.1,5-Hydrogen shift in the intermediate 105 forms the pyrroles 102.

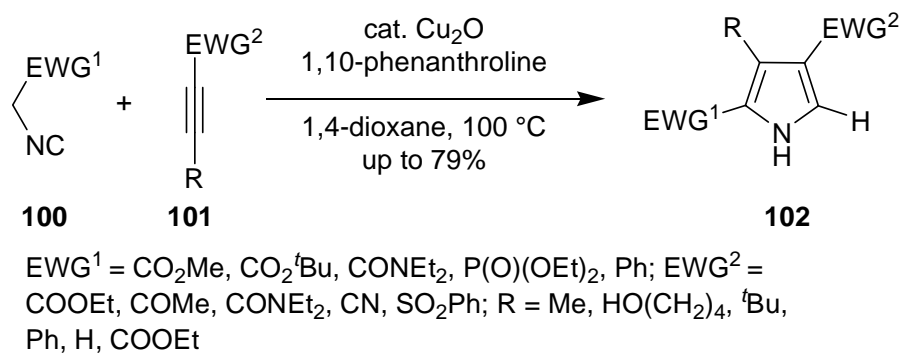

\section{Scheme 30}




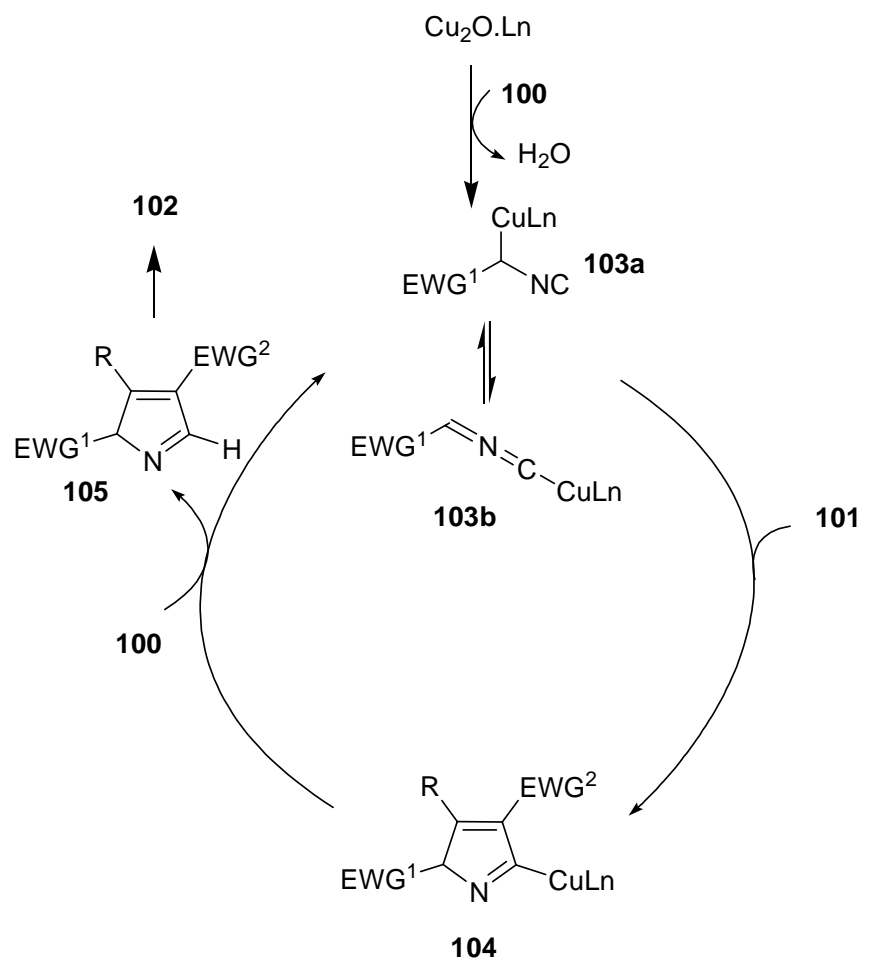

\section{Scheme 31}

Murahashi et al. reported rhodium catalyzed route for the synthesis of pyrroles $\mathbf{1 0 7}$ from isonitriles 100a and 1,3-dicarbonyl compounds 106 (Scheme 32). ${ }^{34}$ The route is based on the activation of $\alpha \mathrm{C}-\mathrm{H}$ bond of isonitriles followed by addition of it to carbonyl compounds (cf 108) proceeds under mild and neutral conditions to give the corresponding $\alpha, \beta$-unsaturated formamides 109. Rhodium catalyzed decarbonylation of $\mathbf{1 0 9}$ followed by cyclocondensation of enamino intermediate 110 would give pyrrole 107.

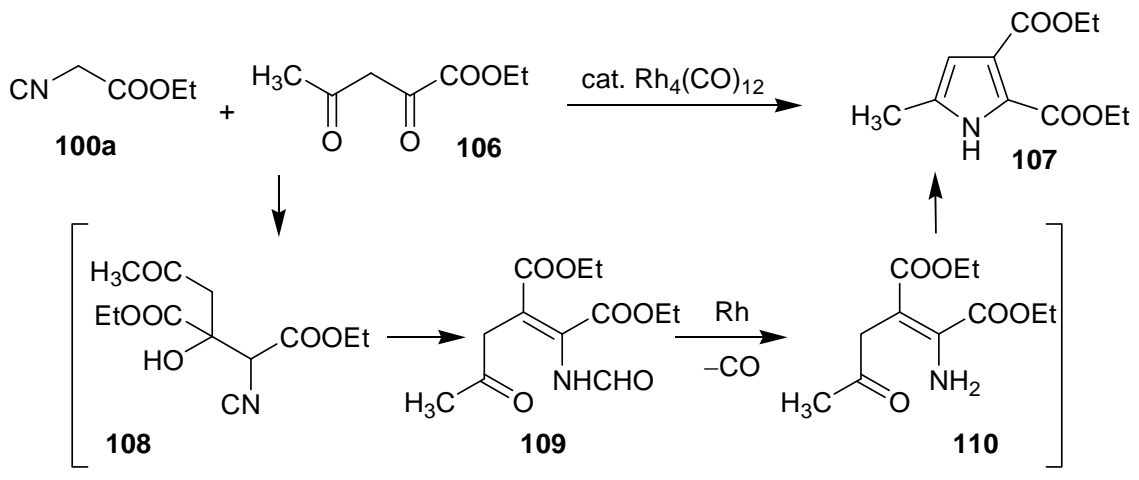

\section{Scheme 32}


The concept of silver catalyzed intramolecular hydroamination to pyrrole synthesis was reported by Dovey and coworkers for the synthesis of $N$-bridgehead pyrroles $\mathbf{1 1 2}$ from amino alkynes 111 using microwave irradiation. The reaction was believed to proceed via intermediate 113 which on proton migration afford products (Scheme 33). ${ }^{35}$

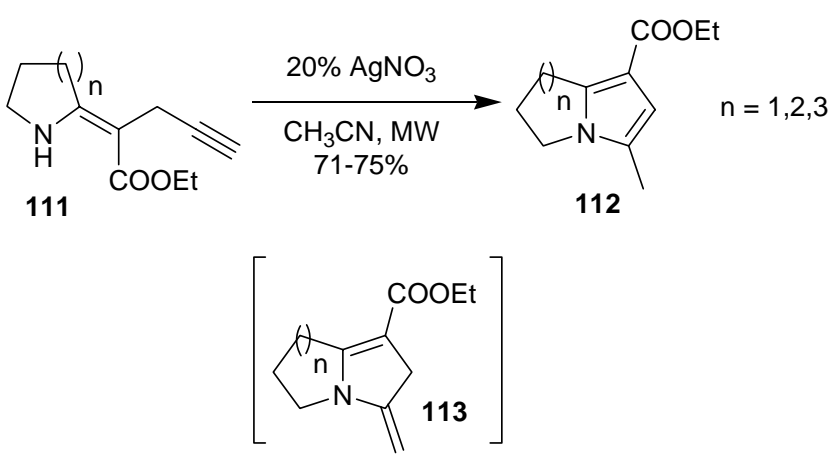

\section{Scheme 33}

The palladium-catalyzed reaction of the methyleneaziridines 114 with $o$-acetylpyridine 115 gave the $o$-pyridinylpyrroles 116 in good to high yields (Scheme 34). ${ }^{36}$ Not only $o$ - but also $\mathrm{m}$ and $p$-acetylpyridines and related substrates can be used as the starting acetyl derivatives. A plausible mechanism is shown in Scheme 35. The oxidative insertion of $\operatorname{Pd}(0)$ into an $\alpha \mathrm{C}-\mathrm{H}$ bond of $o$-acetylpyridine 115 produces the hydridopalladium species 117 (or its oxa- $\pi$-allyl structure 117a), and then the hydropalladation of 114 with 117 takes place as shown in 118. Reductive elimination of palladium may then occur to afford the intermediate 119 and $\operatorname{Pd}(0)$ species. Subsequent cyclization affords the intermediate 120, which after elimination of $\mathrm{H}_{2} \mathrm{O}$ produces 116.

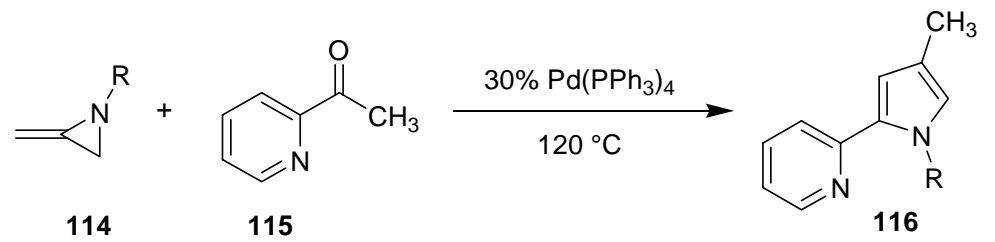

\section{Scheme 34}



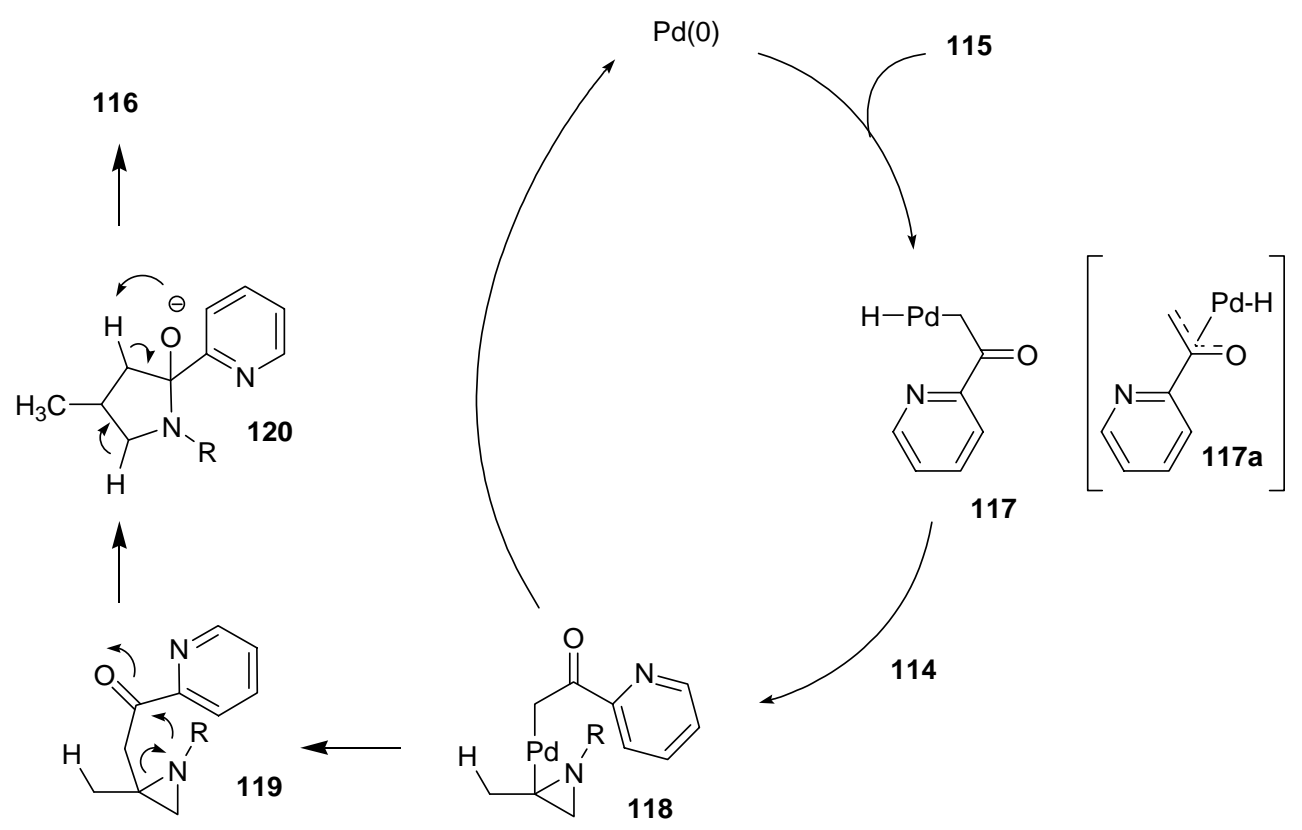

\section{Scheme 35}

Kirsch et al. reported one-pot process for the synthesis of pyrroles 122 from easily accessed propargyl vinyl ethers 121 and aromatic amines (Scheme 36). ${ }^{37}$ The cascade reaction proceeds through a silver(I)-catalyzed propargyl Claisen rearrangement (cf. 123), an amine condensation (cf. 124), and a gold(I)-catalyzed 5-exo-dig heterocyclization.

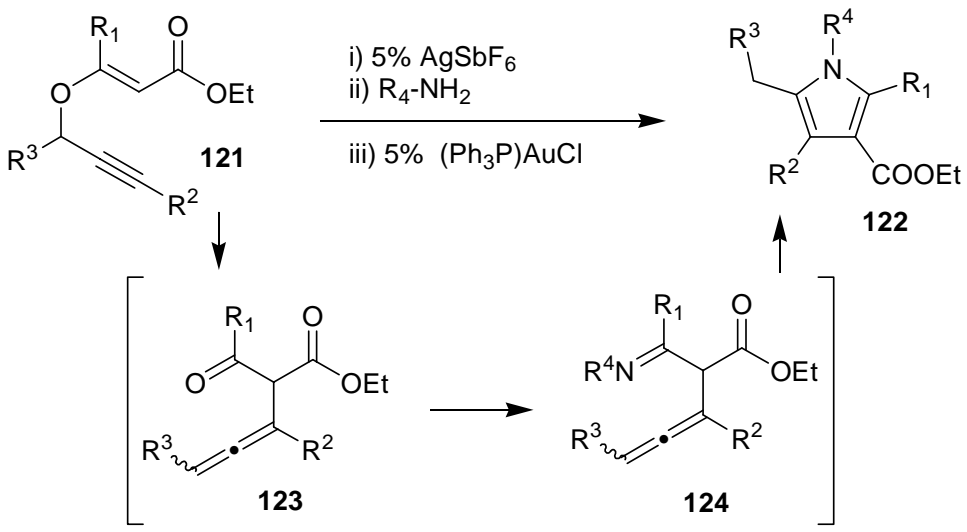

\section{Scheme 36}

Palladium catalyzed multicomponent coupling of alkynes, imines and acid chlorides for the synthesis of multiply substituted pyrroles is reported (Scheme 27). ${ }^{38}$ The approach is based upon the ability of alkynes to undergo 1,3-dipolar addition to 1,3-oxazolium-5-oxides (Munchnones) to form pyrroles. Munchnones $\mathbf{1 2 9}$ are generated from palladium-catalyzed coupling of imines 
125, acid chlorides 126, and carbon monoxide which undergo insitu [3+2] dipolar cycloaddition with 126 to give pyrroles.

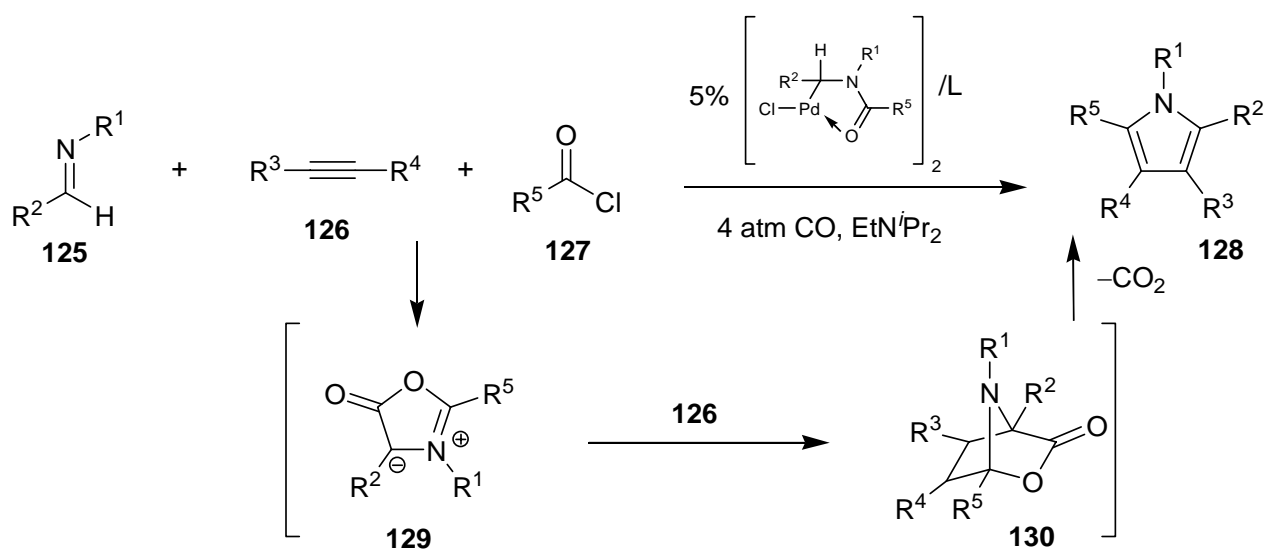

\section{Scheme 37}

The intermolecular hydroamination protocol has been successfully executed for the pyrrole syntheis (Scheme 39). ${ }^{39}$ Titanium-catalyzed hydroamination of 1,4-diynes 131a and 1,5-diynes 131b by primary amines leads to imino-alkynes that undergo in situ 5-endo dig and 5-exodig cyclization reactions, to afford pyrroles 132a and 132b, respectively. It should be noted that the products 1,2,5-trisubsituted pyrroles are accessed directly from readily available diyne starting materials.

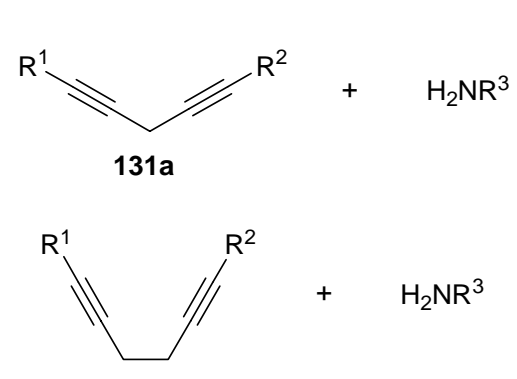

131b
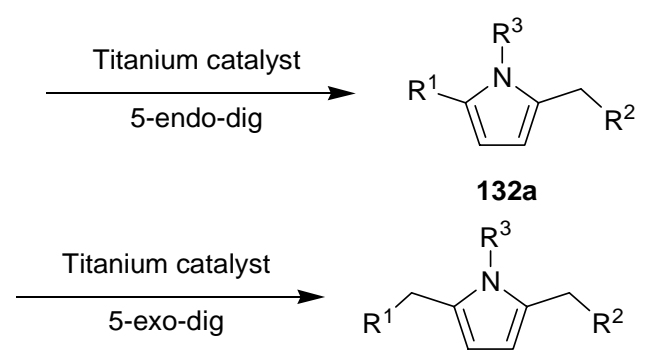

$132 b$

\section{Scheme 38}

In summary, we have described some recent advances in the transition metal mediated synthesis of furans and pyrroles. The most important aspect of the metal mediated synthesis lies in its efficiency, since the reaction can be performed often at lower catalyst loading and at ambient temperature. Moreover, the reaction proceeds under relatively mild conditions and tolerate a wide variety of functional groups. We think that many newer approaches for the synthesis of multiply substituted furans and pyrroles will be appeared in the future. 


\section{References}

1. Sargent, M. V.; Dean, F. M. Comprehensive Heterocyclic Chemistry, Vol. 4 Katrizky, A. R.; Rees C. W., Eds.; Pergamon Press: New York, 1984; pp 599-656; Donnelly, D. M. X.; Meegan, M. J. Comprehensive Heterocyclic Chemistry, Vol. 4, Katrizky, A. R.; Rees, C. W., Eds., Pergamon Press: New York, 1984; pp 657. (b) Natural Products Chemistry, Nakanishi, K. Ed., Kodansha: Toyko, 1974; pp 392. (c) Shipman, M. Contemp. Org. Synth. 1995, 2, 1. (d) Vernin, G.; Vernin, G. Chemistry of Heterocyclic Compounds in Flavours and Aromas, Vernin, G. Ed., Ellis Horwood: Chichester, 1982; pp 74. (e) Vernin, G.; Parkanyi, C. Chemistry of Heterocyclic Compounds in Flavours and Aromas G. Vernin, Ed., Ellis Horwood: Chichester, 1982, pp 161. (f) Lipshutz, B. H. Chem. Rev. 1986, 86, 795.

2. Boger, D. L.; Boyce, C.W.; Labrili, M. A.; Sehon, C. A.; Jin, Q. J. Am. Chem. Soc. 1999, 121, 54. (b) Pyrroles, Part II; Jones, R. A., Ed.; Wiley: New York, 1992. (c) Thompson, R. B. FASEB J. 2001, 15, 1671. (d) Muchowski, J. M. Adv. Med. Chem. 1992, 1, 109. (e) Cozzi, P.; Mongelli, N. Curr. Pharm. Des. 1998, 4, 181. (f) Furstner, A.; Szillat, H.; Gabor, B.; Mynott, R. J. Am. Chem. Soc. 1998, 120, 8305.

3. For reviews on furan synthesis, see: (a) Eberbach, W. Furan. In Houben-Weyl; Thieme: Stuttgart, 1994; E6a, Tail I, p 16. (b) Hou, X. L.; Cheung, H. Y.; Hon, T. Y.; Kwan, P. L.; Lo, T. H.; Tong, S. Y.; Wong, H. N. C. Tetrahedron 1998, 54, 1955. (c) Gilchrist, T. L. J. Chem. Soc., Perkin Trans. 1 1999, 2849. For reviews on pyrrole synthesis, see: (d) Sundberg, R. J. In Comprehensive Heterocyclic Chemistry, Katritzky, A. R.; Rees, C. W.; Scriven, E. F. V. Pergamon: Oxford, 1996; Vol. 2, pp 119. (e) Ferreira, V. F.; De Souza, M. C. B. V.; Cunha, A. C.; Pereira, L. O. R.; Ferreira, M. L. G. Org. Prep. Proced. Int. 2001, $33,411$.

4. (a) Nakamura, I.; Yamamoto, Y. Chem. Rev. 2004, 104, 2127. (b) McReynolds, M. D.; Dougherty, J. M.; Hanson, P. R. Chem. Rev. 2004, 104, 2239. (c) Alonso, F.; Beletskaya, I. P.; Yus, M. Chem. Rev. 2004, 104, 3079. (d) Deiters, A.; Martin, S. F. Chem. Rev. 2004, 104, 2199. (e) Zeni, G.; Larock, R. C. 2004, 104, 2285. (f) Yet, L. Chem. Rev. 2000, 100, 2963. (g) Tsuji, J. Transition Metal Reagents and Catalysts; John Wiley: New York, 2000. (h) Transition Metals for Organic Synthesis; Beller, M., Bolm, C., Eds.; Wiley-VCH: Weinheim, 1998. (i) Transition Metal Catalysed Reactions; Murahashi, S., Davies, S. G., Eds.; Blackwell Science: Oxford, 1999.

5. Quite recently a general report appeared on the synthesis of these heterocycles, see: (a) Kirsch, S. F. Org. Biomol. Chem. 2006, 4, 2076. (b) Brown, R. C. D. Angew. Chem. Int. Ed. 2005, 44, 850. (c) Balme, G. Angwe. Chem. Int. Ed. 2004, 43, 6238.

6. Hashmi, A. S. K.; Schwarz, L.; Choi, J.-H.; Frost, T. M. Angew. Chem., Int. Ed. 2000, 39, 2285.

7. Zhou, C-Y.; Chan, P. W. H.; Che, C-M. Org. Lett. 2006, 8, 325.

8. Sromek, A. W.; Rubina, M.; Gevorgyan, V. J. Am. Chem. Soc. 2005, 127, 10500.

9. Kelin, A. V.; Gevorgyan, V. J. Org. Chem. 2002, 67, 95. 
10. Kim, J. T.; Kelin, A. V.; Gevorgyan, V. Angew. Chem. Int. Ed. 2003, 42, 98.

11. Sromek, A. W.; Kelin, A. V.; Gevorgyan, V. Angew. Chem. Int. Ed. 2004, 43, 2280.

12. Ma, S.; Zhang, J.; Lu, L. Chem. Eur. J. 2003, 9, 2447.

13. Hashmi, A. S. K.; Sinha, P. Adv. Synth. Catal. 2004, 346, 432.

14. Suhre, M. H.; Reif, M.; Kirsch, S. F. Org. Lett. 2005, 7, 3925.

15. Yao, T.; Zhang, X.; Larock, R. C. J. Am. Chem. Soc. 2004, 126, 11164.

16. Patil, N. T.; Wu, H.; Yamamoto, Y. J. Org. Chem. 2005, 70, 4531.

17. Zhang, J.; Schmalz, H.-G. Angew. Chem. Int. Ed. 2006, 45, 6704.

18. Ma, S.; Zhang, J. J. Am. Chem. Soc. 2003, 125, 12386.

19. Ma, S.; Lu, L.; Zhang, J. J. Am. Chem. Soc. 2004, 126, 9645.

20. Liu, Y.; Song, F.; Song, Z.; Liu, M.; Yan, B. Org. Lett. 2005, 7, 5409.

21. Garcon, S.; Vassiliou, S.; Cavicchioli, M.; Hartmann, B.; Monteiro, N.; Balme, G. J. Org. Chem. 2001, 66, 4069.

22. Karpov, A. S.; Merkul, E.; Oeser, T.; Muller, T. J. J. J. Chem. Soc.Chem. Commun. 2005, 2581.

23. Han, X.; Widenhoefer, R. A. J. Org. Chem. 2004, 69, 1738.

24. Kelin, A. V.; Sromek, A. W.; Gevorgyan, V. J. Am. Chem. Soc. 2001, 123, 2074.

25. Kim, J. T.; Gevorgyan, V. Org. Lett. 2002, 4, 4697.

26. Seregin, I. V.; Gevorgyan, V. J. Am. Chem. Soc. 2006, 128, 12050.

27. Gabriele, B.; Salerno, G.; Fazio, A. J. Org. Chem. 2003, 68, 7853.

28. Arcadi, A.; Giuseppe, S. D.; Marinelli, F.; Rossi, E. Adv. Synth. Catal. 2001, 343, 443.

29. Harrison, T. J.; Kozak, J. A.; Corbella-Pane, M.; Dake, G. R. J. Org. Chem. 2006, 71, 4525.

30. Martin, R.; Rivero, M. R.; Buchwald, S. L. Angew. Chem. Int. Ed. 2006, 45, 7079.

31. Gorin, D. J.; Davis, N. R.; Toste, F. D. J. Am. Chem. Soc. 2005, 127, 11260.

32. Hiroya, K.; Matsumoto, S.; Ashikawa, M.; Ogiwara, K.; Sakamoto, T. Org. Lett. 2006, 8, 5349.

33. Kamijo, S.; Kanazawa, C.; Yamamoto, Y. J. Am. Chem. Soc. 2005, 127, 9260.

34. Takaya, H.; Kojima, S.; Murahashi, S.-I. Org. Lett. 2001, 3, 421.

35. (a) Robinson, R. S.; Dovey, M. C.; Gravestock, D. Tetrahedron Lett. 2004, 45, 6787. See also: (b) Robinson, R. S.; Dovey, M. C.; Gravestock, D. Eur. J. Org. Chem. 2005, 505. (c) Gravestock, D.; Dovey, M. C. Synthesis 2003, 523.

36. Siriwardana, A. I.; Kathriarachchi, K. K. A. D. S.; Nakamura, I.; Gridnev, I. D.; and Yamamoto, Y. J. Am. Chem. Soc. 2004, 126, 13898.

37. Binder, J. T.; Kirsch, S. F. Org. Lett. 2006, 8, 2151.

38. Dhawan, R.; Arndtsen, B. A. J. Am. Chem. Soc. 2004, 126, 468.

39. Ramanathan, B.; Keith, A. J.; Armstrong, D.; Odom, A. L. Org. Lett. 2004, 6, 2957. 